\title{
EFFECTS OF THERMAL EFFLUENTS FROM THE BERGUM POWER STATION ON THE ZOOPLANKTON IN LAKE BERGUM
}

\author{
H.W. DE NIE \\ (Limnological Institute, Tjeukemeer Laboratory, 8536 VD Oosterzee, The Netherlands) \\ The aim of the investigations was to describe the effects on the population dynamics \\ of the zooplankton (microcrustaceans and rotifers) in Lake Bergum. The discharges started \\ in August 1974. Not much is known about the zooplankton populations in Lake Bergum \\ before this date. Since 1968 the Tjeukemeer (one of the largest Friesian lakes) is \\ Intensively studied by the members of the Limnological Institute. Whereas the zooplankton \\ communities of the different Friesian lakes are very similair (BEATTIE et al., 1978), it \\ was feasible to compare the zooplankton population dynamics of Lake Bergum and \\ Tjeukemeer. \\ During 1975, 1976 and 1977 an extensive sampling program was carried out in Lake \\ Bergum. Samples were taken weekly during the growing season and fortnightly from \\ October until April. Additionally, fortnightly sampling was carried out in 1978. The samples \\ were collected at 8 different points in the lake, enabling comparison between various \\ locations near the outlet and locations which were not heated at all.
}

Effects on the population dynamics.

Comparison of zooplankton numbers in the Tjeukemeer and Lake Bergum in 1975, 1976 and 1977 learned that there was no difference in the species composition, the periods of increase, and the moment of maximum abundance. Differences in the relative abundance and the period of decrease were probably caused by other factors than thermal discharges. The zooplankton density throughout the year was about the same for all sampling pionts within Lake Bergum. The periods of increase and decrease were exactly the same.

Entrainment effects.

Near the outlet the zooplankton densities at the surface water layer decreased 20 to $30 \%$ in numbers. The cladocerans Bosmina longirostris, B. coregoni, Chydorus sphaericus and Daphnia sp. and the copepodites of the cyclopoids (mainly Acanthocyclops robustus) showed higher densities in deeper water near the outlet. At 1.5 to $2.0 \mathrm{~km}$ from the outlet we found 'normal' densities at the surface and no concentration in deeper water. A vital staining technique was used to investigate the entrainment mortality of the cladocerans. The average increase in mortality during $3.5 \mathrm{hrs}$ incubation at outlet temperature ranged between 2 and $3 \%$. The entrainment mortality of Leptodore kindtii and the naupliar larvea of the cyclopoids could not be investigated by this technique. For these organisms we compared densities on different depths. Average percentual mortalities ranged from 19 to $33 \%$ for $L$. kindtii and from 25 to $28 \%$ for the naupliar larvea of the cyclopoids. The effect of this mortality on the population dynamics of the zooplankton in Lake Bergum could not be determined because of a constant water flow from the power station to other water bodies.

The "Ministerie van Volksgezondheid en Milieuhygiëne" (Ministry of Public Health and the Environment) financially supported this research project. An extensive report (in Dutch) will be published this year.

\section{References}

BEATTIE, D.M., H.L. GOLTERMAN and J. VIJVERBERG, 1978. An introduction to the limnology of the Friesian Lakes. Hydrobiologia, 58:49-64. 